\title{
Computational Molecular Nanoscience Study of the Properties of Copper Complexes for Dye-Sensitized Solar Cells
}

\author{
Jesús Baldenebro-López ${ }^{1,2}$, José Castorena-González ${ }^{2}$, Norma Flores-Holguín ${ }^{1}$, \\ Jorge Almaral-Sánchez ${ }^{2}$ and Daniel Glossman-Mitnik ${ }^{1, *}$ \\ 1 Centro de Investigación en Materiales Avanzados, S.C., Miguel de Cervantes 120, \\ Complejo Industrial Chihuahua, Chihuahua 31190, Mexico; \\ E-Mails: jesus.baldenebro@cimav.edu.mx (J.B.-L.); norma.flores@cimav.edu.mx (N.F.-H.) \\ 2 Universidad Autónoma de Sinaloa, Prol. Ángel Flores y Fuente de Poseidón, S.N., Los Mochis, \\ Sinaloa 81223, Mexico; E-Mails: kstor28@yahoo.com.mx (J.C.-G.); jalmaral@gmail.com (J.A.-S.) \\ * Author to whom correspondence should be addressed; E-Mail: daniel.glossman@cimav.edu.mx; \\ Tel.: +52-614-439-1151; Fax: +52-614-439-1130.
}

Received: 20 August 2012; in revised form: 9 October 2012 / Accepted: 12 November 2012 / Published: 28 November 2012

\begin{abstract}
In this work, we studied a copper complex-based dye, which is proposed for potential photovoltaic applications and is named $\mathrm{Cu}$ (I) biquinoline dye. Results of electron affinities and ionization potentials have been used for the correlation between different levels of calculation used in this study, which are based on The Density Functional Theory (DFT) and time-dependent (TD) DFT. Further, the maximum absorption wavelengths of our theoretical calculations were compared with the experimental data. It was found that the M06/LANL2DZ + DZVP level of calculation provides the best approximation. This level of calculation was used to find the optimized molecular structure and to predict the main molecular vibrations, the molecular orbitals energies, dipole moment, isotropic polarizability and the chemical reactivity parameters that arise from Conceptual DFT.
\end{abstract}

Keywords: molecular structure; absorption spectra; polarizability; chemical reactivity; dipole moment; copper complex; dye-sensitized 


\section{Introduction}

The current warming of the global climate is the result of an increase in greenhouse gas (GHG) emissions, particularly $\mathrm{CO}_{2}$. Global average atmospheric $\mathrm{CO}_{2}$ has increased from $280 \mathrm{ppm}$ in the 1750 s to $389 \mathrm{ppm}$ in 2010 [1-3]. An increasing demand for energy in the emerging economies and energy crisis worldwide has stimulated a growing number of researches on renewable energy, in that the utilization of renewable energy can help reduce fossil fuel consumption and alleviate environmental problems. Renewables-based power systems provide an opportunity to generate cleaner electricity with a lower cost of energy [4]. It is thought that the transition from fossil fuels to a diversified energy matrix can be accelerated by governments by means of adequate policies and instruments that support the creation of incentives for mitigation of greenhouse gases (GHG) emissions and investments in renewable energy technology research and development. Solar energy is one of the most promising sources of energy in the future and one of the renewable energy resources that has long played a dominant role in the field of energy research with its wide application and great potential $[5,6]$. Recently, dye sensitized solar cells (DSSC) [7-9], considered as a credible alternative to conventional inorganic silicon-based solar cells, have attracted attention due to their efficiency, simple manufacturing and low cost [10-13]. In these DSSC, an organic sensitizer must be chemically absorbed on the porous surface of the nanocrystalline oxide. After absorbing a photon, the excited electron in the dye-sensitized molecule is transferred into the conduction band of nanocrystalline oxide, followed by a process in which the electron diffuses through the electrode. The sensitizer in this oxidized state is reduced to its normal state gaining electrons through a liquid electrolyte [14-16]. Nowadays, many research groups from all over the world actively participate to improve the efficiency of every single process involved in the DSSC [17-19]. The charge transfer efficiency from the dye molecule to the nanocrystalline oxide is extremely important in the solar cell design. Since Regal and Grätzel published their pioneer study [7], the understanding of the mechanism has required fundamental research about the diverse physical phenomena at nanometric scale [20]. Theoretical studies on physical and chemical properties of dye-sensitizers are very important to understand the relationship between the structure, properties and performance in order to design and synthesize new molecules for this purpose [21-24].

Ruthenium(II) complexes as dyes have been extensively used as sensitizers in DSSCs owing to their strong absorption in the visible range and relatively long-lived excited states [25]. The strong absorptivity of these complexes is due to a metal-to-ligand charge transfer (MLCT) transition [26]. These complexes have reached over $12 \%$ power conversion efficiency [27]; but the rarity and high cost of the $\mathrm{Ru}$ may limit their practical usage. Since initial reports of a $\left[\mathrm{Ru}(\mathrm{bpy})_{3}\right]^{2+}$-based (bpy $=2,2^{\prime}$-bipyridine) photosensitizer, the dyes reported in the literature have predominantly been ruthenium(II) complexes. We have recently become interested in the study and optimization of copper(I)-based DSSC, literature reports of which are scarce. Sauvage and co-workers [28] discovered that copper(I) complexes have similar photo-physical properties with Ru complexes, indicating that the iterative chemical optimization of common metal complexes sensitizers can be comparable to that of $\mathrm{Ru}$ complexes [29]. Copper(I) complexes display a wide variety of excited states and especially photophysical and photochemical processes. Particularly, copper(I)-poly-pyridine complexes exhibit low-lying MLCT transitions that can participate, among others, in electron transfer processes [30]. In 
this research, we propose the study of a molecular system of this type, such as $\left[\mathrm{Cu}(\mathrm{LL})_{2}\right]^{+}$ ( $\mathrm{LL}=2,2^{\prime}$-biquinoline-4,4'-dicarboxylic acid) which is shown in Figure 1 ( $\mathrm{Cu}(\mathrm{I})$ biquinoline), in order to define from the theoretical point of view a suitable calculation methodology for obtaining structural parameters, as well as electrical and optical properties using the density functional theory (DFT) [31-33] and time-dependent (TD) DFT [34-36]. These methods are implemented in the Gaussian 09W program package [37]. In this paper, we have found very interesting properties with the proposed ligand to increase the level of conjugation, which has not been reported as an article in the DSSC field.

Figure 1. Molecular structure of copper complex.

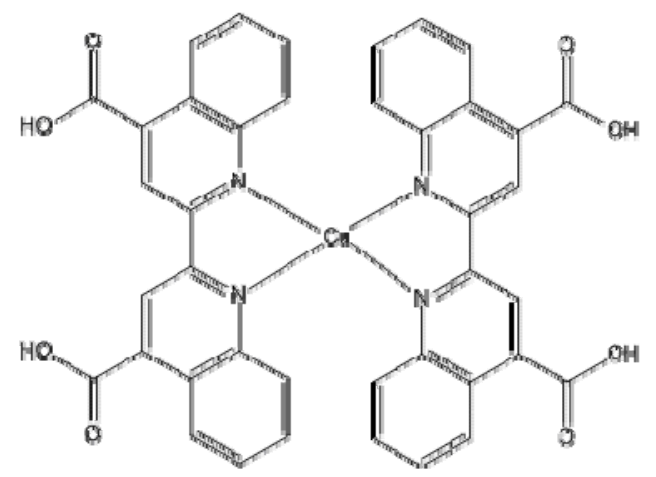

\section{Results and Discussion}

Once the molecular structure was proposed, the geometry optimization was calculated, followed by the frequency analysis to confirm that the species had the minimum energy conformation. These calculations were performed in the presence of methanol as solvent.

The electron affinity (A) and the ionization potential (I) were obtained by energy calculations (neutral and ionic state), taking into account the ground state geometry optimization. The aim of this was to establish the correlation of results between the different levels of calculation, since there are no experimental results reported for this system; this is a contribution of our research. Table 1 shows the values obtained and where it seems as if some of these have variations between them.

Figure 2 helps to visualize more clearly the dispersion of these values. M06-HF/LANL2DZ-DZVP, M06-2X/6-31G(d) + DZVP and M06-HF/6-31G(d) + DZVP levels of theory show the greatest dispersion; therefore, the values are ignored for the calculation of some measures of central tendency, such as the mean and median. The red line represents the mean value, in the case of electron affinity, it is located at $4.75 \mathrm{eV}$ and for the ionization potential it is equal to $9.75 \mathrm{eV}$; meanwhile, the medium has the values of $4.79 \mathrm{eV}$ and $9.80 \mathrm{eV}$, respectively. This led to results of the population standard deviation of 0.1555 (in A) and 0.1768 (in I) with a coefficient of variation of $3.27 \%$ and $1.81 \%$, which are values of high quality. On this basis, we can establish that the model chemistry M06/LANL2DZ + DZVP and PBE0/LANL2DZ + DZVP represent excellent approximations in this context. 
Table 1. Electron affinity and the ionization potential of $\mathrm{Cu}(\mathrm{I})$ biquinoline with different levels of theory.

\begin{tabular}{cccc}
\hline Basis set & Functional & Electron affinity $(\mathbf{e V})$ & Ionization potential (eV) \\
\hline LANL2DZ + DZVP & M06 & 4.79 & 9.80 \\
& M06-2X & 4.65 & 9.93 \\
& M06-HF & 4.58 & 11.86 \\
& M06-L & 4.98 & 9.55 \\
& B3LYP & 4.88 & 9.84 \\
& PBE0 & 4.79 & 9.79 \\
LANL2DZ & M06 & 4.82 & 9.90 \\
& M06-2X & 4.64 & 10.01 \\
& M06-HF & 4.57 & 9.63 \\
& M06-L & 5.00 & 9.48 \\
$6-31 G(d)+$ DZVP & M06 & 4.49 & 9.87 \\
& M06-2X & 4.26 & 11.01 \\
& M06-HF & 4.12 & 11.61 \\
& M06-L & 4.69 & 9.49 \\
\hline
\end{tabular}

Figure 2. Electron affinity and ionization potential for the levels of theory used in this study and the dispersion between the values. The red line represents the mean value, in the case of electron affinity it is located at $4.75 \mathrm{eV}$ and in the case of ionization potential it is equal to $9.75 \mathrm{eV}$.

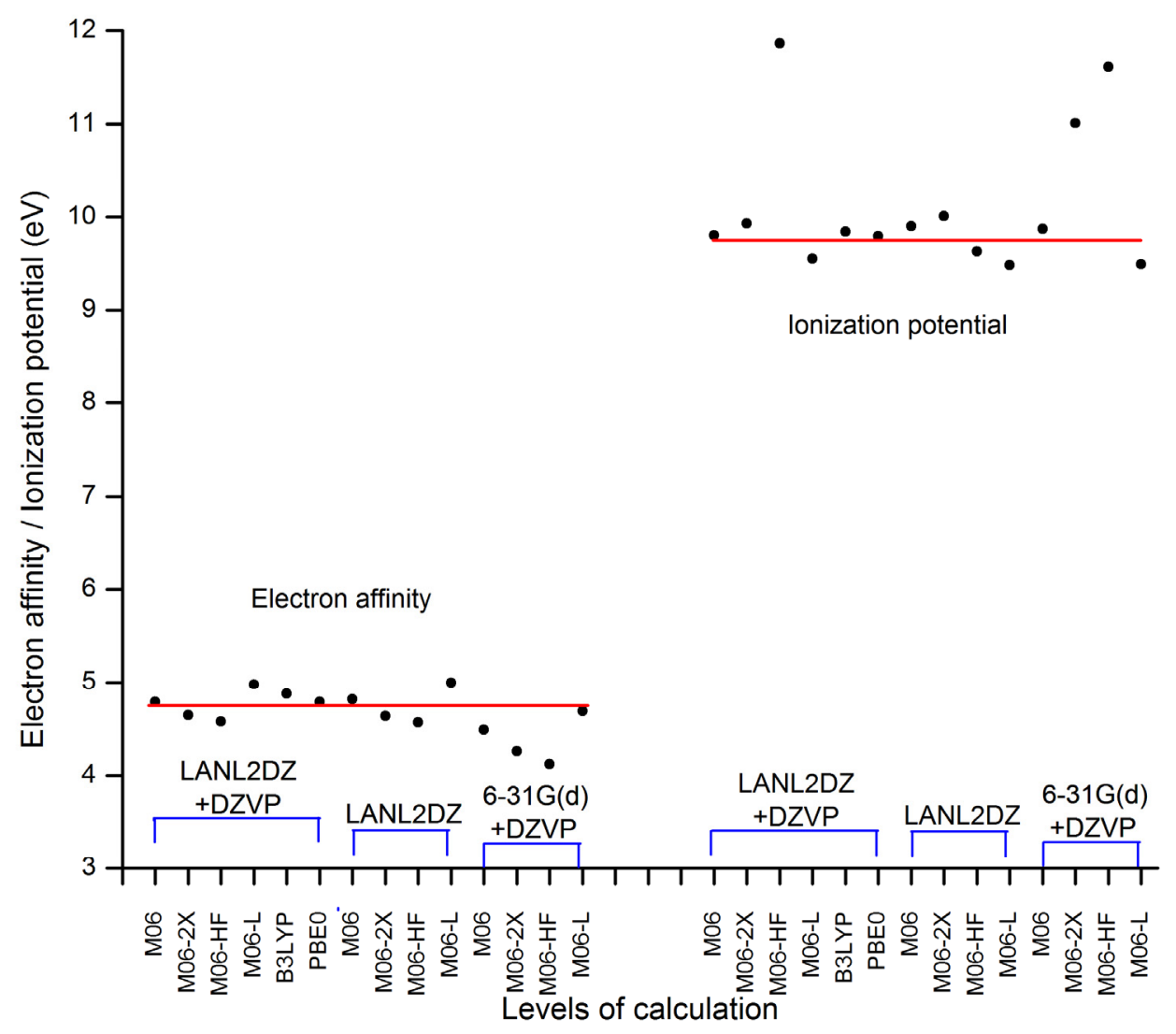


Another fundamental property as a potential sensitizer for DSSC is the maximum absorption wavelength $\left(\lambda_{\max }\right)$; according to the levels of theory selected, the UV-Vis spectrum and the $\lambda$ max were calculated. The results of $\lambda_{\max }$ are shown in Table 2 .

The results in Table 2 show that $\lambda$ max varies from a high value to a low value when the functional increases the percentage of Hartree-Fock exchange. The experimental result indicates that $\lambda \max$ is $553 \mathrm{~nm}$ [38]. Comparing this result with our calculation, we can conclude that the calculation methodology with more precision is M06/LANL2DZ + DZVP. Similarly, by comparing the results of A, I and $\lambda \max$, this methodology will be used to study other properties of the dye under investigation. Another aspect to consider is that using a LANL2DZ basis set better describes the behavior of the excited states of the ligand molecule.

Table 2. Maximum absorption wavelength of $\mathrm{Cu}(\mathrm{I})$ biquinoline dye using various models.

\begin{tabular}{cccc}
\hline Model chemistry & $\boldsymbol{\lambda}_{\max }(\mathbf{n m})$ & Model chemistry & $\boldsymbol{\lambda}_{\max }(\mathbf{n m})$ \\
\hline M06/LANL2DZ + DZVP & 556 & M06-HF/LANL2DZ & 282 \\
M06-2X/LANL2DZ + DZVP & 386 & M06/LANL2DZ & 543 \\
M06-HF/LANL2DZ + DZVP & 279 & M06-2X/LANL2DZ & 378 \\
M06-L/LANL2DZ + DZVP & 641 & M06-L/6-31G(d) + DZVP & 645 \\
B3LYP/LANL2DZ + DZVP & 614 & M06-HF/6-31G(d) + DZVP & 279 \\
PBE0/LANL2DZ + DZVP & 578 & M06/6-31G(d) + DZVP & 488 \\
M06-L/LANL2DZ & 629 & M06-2X/6-31G(d) + DZVP & 328 \\
\hline
\end{tabular}

Figure 3 shows the UV-Vis spectra at the M06/LANL2DZ-DZVP level of calculation and its corresponding $\lambda \max (556 \mathrm{~nm})$. The calculated value of $\lambda \max$ indicates that this molecular system should be considered for use as a functional material (as dye in this case) in a DSSC, the value of this parameter for the $\mathrm{Cu}(\mathrm{I})$ biquinoline dye meets the requirements established in the literature [39].

Figure 3. UV-Vis spectra of $\mathrm{Cu}(\mathrm{I})$ biquinoline dye at the M06/LANL2DZ-DZVP level of calculation.

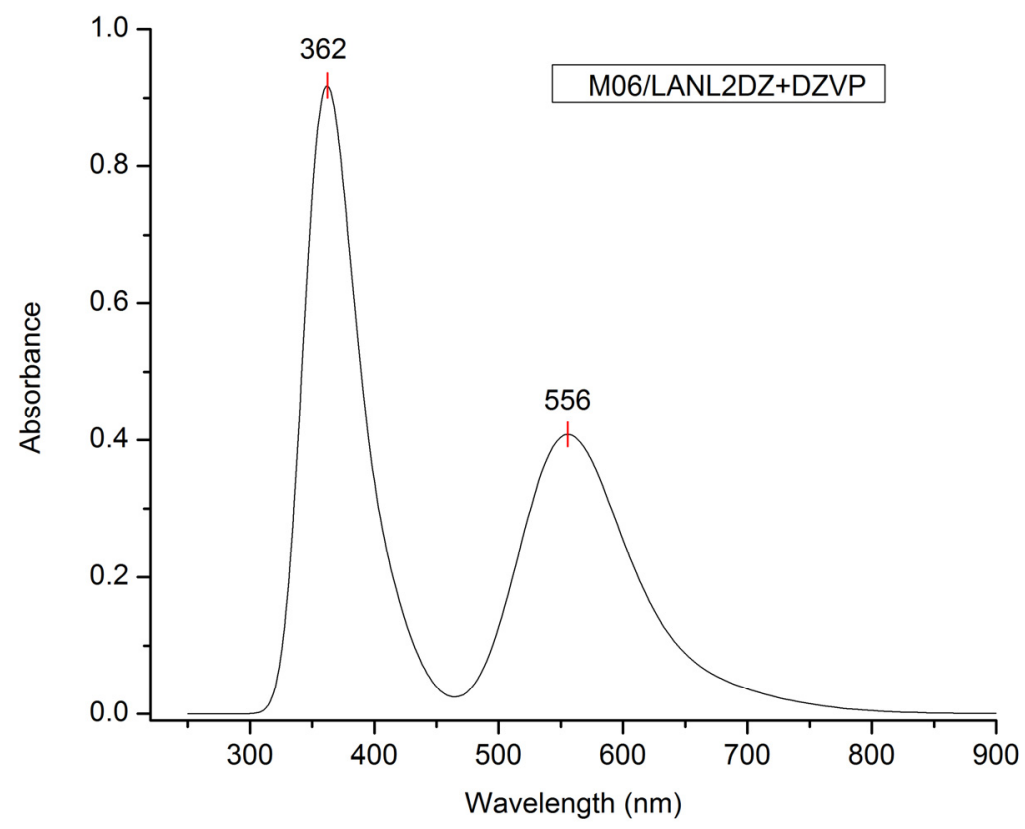


Table 3 shows the result of time-dependent density functional theory (TD-DFT) calculation; including the corresponding wavelengths (in $\mathrm{nm}$ ), the energies (in $\mathrm{eV}$ ), the oscillator strength (f) and the orbitals involved in the transitions. This information shows that the peak of the wavelength of maximum absorption (556 $\mathrm{nm}$ ) is due to charge transfer between the metal atom and the ligand molecule (MLCT). The spectrum of $\mathrm{Cu}(\mathrm{I})$ biquinoline also showed intense absorption in the UV region assigned to ligand-based $\pi^{*}-\pi$ transition (362 $\mathrm{nm}$ ).

Table 3. $\mathrm{Cu}(\mathrm{I})$ biquinoline electronic excited states, showing wavelengths (nm), energies $(\mathrm{eV})$, oscillator strength (f) and the orbitals involved in the transitions. Only excited states with oscillator strength $>0.02$ are shown.

\begin{tabular}{cccc}
\hline $\boldsymbol{\lambda}(\mathbf{n m})$ & $\boldsymbol{E}(\mathbf{e V})$ & $\begin{array}{c}\text { Oscillator } \\
\text { strength }\end{array}$ & Assignment; H HOMO, L $=$ LUMO, L + 1 $=$ LUMO + 1, etc. \\
\hline 556.0 & 2.25 & 0.1652 & $\mathrm{H}-1 \rightarrow \mathrm{L}+1(50 \%) \mathrm{H}-0 \rightarrow \mathrm{L}+0(26 \%) \mathrm{H}-1 \rightarrow \mathrm{L}+0(19 \%)$ \\
373.3 & 3.32 & 0.0308 & $\mathrm{H}-3 \rightarrow \mathrm{L}+0(76 \%) \mathrm{H}-2 \rightarrow \mathrm{L}+0(8 \%) \mathrm{H}-4 \rightarrow \mathrm{L}+0(6 \%)$ \\
362.0 & 3.40 & 0.0372 & $\mathrm{H}-3 \rightarrow \mathrm{L}+1(54 \%) \mathrm{H}-2 \rightarrow \mathrm{L}+1(9 \%) \mathrm{H}-5 \rightarrow \mathrm{L}+1(8 \%)$ \\
& & & $\mathrm{H}-4 \rightarrow \mathrm{L}+1(7 \%) \mathrm{H}-1 \rightarrow \mathrm{L}+3(5 \%)$ \\
358.7 & 3.46 & 0.0225 & $\mathrm{H}-6 \rightarrow \mathrm{L}+0(43 \%) \mathrm{H}-10 \rightarrow \mathrm{L}+0(16 \%) \mathrm{H}-2 \rightarrow \mathrm{L}+0(13 \%)$ \\
& & & $\mathrm{H}-9 \rightarrow \mathrm{L}+0(8 \%) \mathrm{H}-5 \rightarrow \mathrm{L}+0(8 \%)$ \\
355.3 & 3.49 & 0.0295 & $\mathrm{H}-5 \rightarrow \mathrm{L}+1(67 \%) \mathrm{H}-5 \rightarrow \mathrm{L}+0(11 \%) \mathrm{H}-3 \rightarrow \mathrm{L}+1(10 \%)$ \\
351.6 & 3.53 & 0.0392 & $\mathrm{H}-6 \rightarrow \mathrm{L}+0(39 \%) \mathrm{H}-10 \rightarrow \mathrm{L}+0(23 \%) \mathrm{H}-9 \rightarrow \mathrm{L}+0(15 \%)$ \\
& & & $\mathrm{H}-2 \rightarrow \mathrm{L}+0(9 \%)$ \\
\hline
\end{tabular}

There are theoretical studies on copper complexes reported by X. Lu et al. [40], they used the B3LYP functional with 6-31G(d) and DZVP basis sets and obtained a value of $\lambda_{\max }$ equal to $543 \mathrm{~nm}$; compared with the experimental result of $492 \mathrm{~nm}$ by E. Constable et al. [41], we can note the good approximation of this level of calculation. However, the proposed methodology with the M06 functional is more suitable due to lower error.

In their recent study on copper complexes, E. Constable et al., 2010 [42] propose to incorporate substituents at the 6-6' positions with imine-based ligands to protect the metal center and modulate the redox properties. The reached value of $\lambda_{\max }$ is $511 \mathrm{~nm}$, which is less than for the system proposed in this study.

The optimized structure of $\mathrm{Cu}(\mathrm{I})$ biquinoline dye is shown in Figure 4, including the numbers of atoms and symbols. This geometry was obtained in the presence of methanol as solvent and the integral equation formalism polarizable continuum model (IEF-PCM) model.

A selection of geometric parameters was made to clearly visualize how the geometric structure has a very small structural variation of the atoms bonded with respect to the characteristic lengths and angles reported in the literature [28]. Table 4 shows the selected values for bond length $(\AA)$ and bond angles (in degrees).

Another very interesting research by X. Lu et al. 2011 [43] presents the molecular structures of eight copper complexes which display the results for bond lengths of 1.987 to $2.002 \AA$ between the copper and nitrogen atoms, the bond angles vary from $82.8^{\circ}$ to $83.2^{\circ}$. These values are very close to the typical ranges of $2.003 \AA$ to $2.039 \AA$ and $80.93^{\circ}$ to $81.21^{\circ}$, which were reported by T. Bessho et al. 
in 2008 [41]. Considering the Table 4, the calculated values vary from $2.022 \AA$ to $2.025 \AA$, while the bond angles are estimated at $81.6^{\circ}$. This shows the excellent approximation on the level of theory.

Figure 4. Optimized molecular structure of $\mathrm{Cu}(\mathrm{I})$ biquinoline dye with M06/LANL2DZ + DZVP level of calculation.

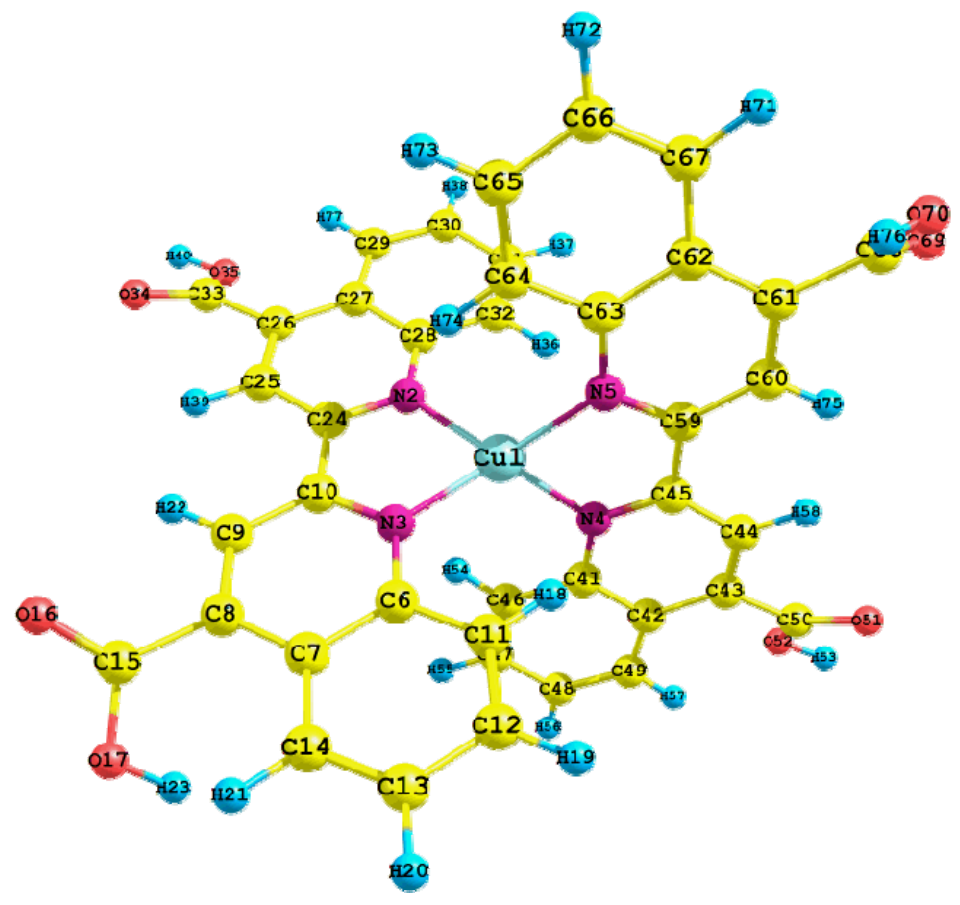

Table 4. $\mathrm{Cu}(\mathrm{I})$ biquinoline dye selected bond lengths (angstroms) and bond angles (degrees).

\begin{tabular}{cccc}
\hline Parameters & Value & Parameters & Value \\
\hline Cu1-N2 & 2.024 & C50-O52 & 1.349 \\
Cu1-N3 & 2.023 & O52-H53 & 1.034 \\
Cu1-N4 & 2.022 & Cu1-N2-C28 & 126.0 \\
Cu1-N5 & 2.025 & Cu1-N2-C24 & 113.4 \\
N4-C45 & 1.342 & N2-Cu1-N5 & 121.4 \\
N4-C41 & 1.374 & N2-Cu1-N3 & 81.6 \\
C45-C59 & 1.477 & N2-Cu1-N4 & 128.5 \\
C41-C42 & 1.437 & N3-Cu1-N4 & 122.0 \\
C44-H58 & 1.089 & N3-Cu1-N5 & 128.2 \\
C50-O51 & 1.245 & N4-Cu1-N5 & 81.6 \\
\hline
\end{tabular}

In infrared (IR) spectral calculation (Figure 5), the vibrational bands indicate the presence of $\mathrm{C}-\mathrm{H}$, $\mathrm{O}-\mathrm{H}, \mathrm{C}=\mathrm{O}$ and $\mathrm{C}-\mathrm{C}$ bonds. The stretching vibration of the aromatic ring $\mathrm{C}-\mathrm{H}$ bond is observed at $3164 \mathrm{~cm}^{-1}$. The $\mathrm{O}-\mathrm{H}$ bond stretching vibration appears at $2533 \mathrm{~cm}^{-1}$, while another peak due to the vibration of $\mathrm{C}=\mathrm{O}$ is present at $1707 \mathrm{~cm}^{-1}$. The vibration of the $\mathrm{C}-\mathrm{C}$ bonds occurs at $1403 \mathrm{~cm}^{-1}$ and the bending of $\mathrm{C}-\mathrm{H}$ in the rings is shown at $1277 \mathrm{~cm}^{-1}$. At $1100 \mathrm{~cm}^{-1}$, the corresponding vibration appears for the bending of the $\mathrm{O}-\mathrm{H}$ bond. The out-of-plane bending vibration associated with the aromatic rings is observed at $807 \mathrm{~cm}^{-1}$. All signals are described in the typical ranges. This calculation, besides 
checking the minimum energy structure, also helps to elucidate the infrared spectra because this has not been reported in the literature up to now.

Figure 5. Infrared spectra of $\mathrm{Cu}(\mathrm{I})$ biquinoline dye.

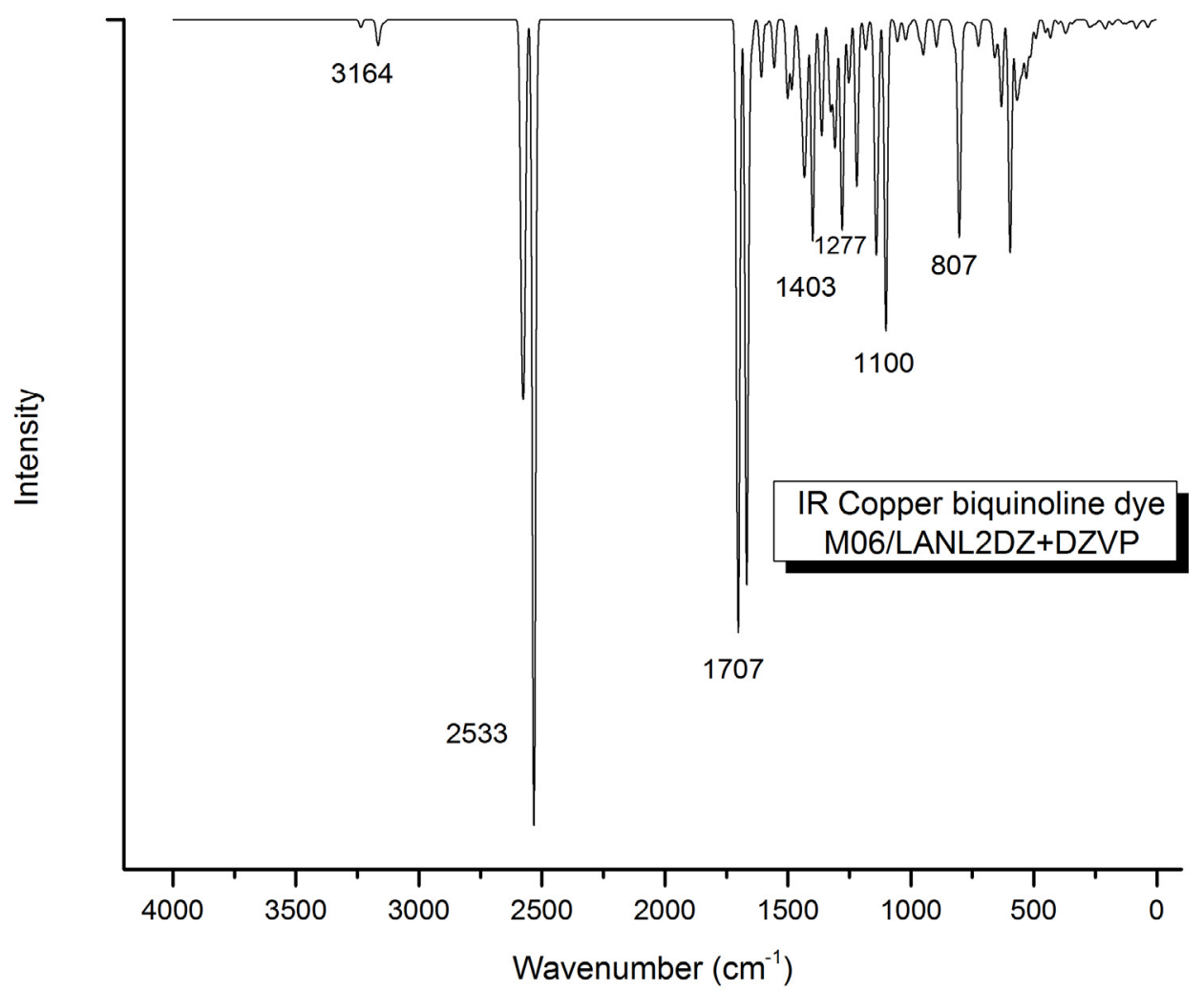

The charge transfer efficiency from the dye molecule to the nanocrystalline oxide is extremely important in the solar cell design. Since the crucial electronic excitations occur from the highest occupied molecular orbitals (HOMO) to the lowest unoccupied molecular orbitals (LUMO), it is therefore important to form efficient charge-separated states with the HOMO localized on the donor subunit and the LUMO on the acceptor subunit. In this molecular system, Figure 6 shows that the HOMO orbital density is located around the copper atom; meanwhile, the density of the LUMO orbital is in the ligand and tends to move toward the carboxyl groups. This is beneficial in accordance with the above-mentioned.

The HOMO-LUMO molecular orbitals' energetic position is another factor to consider, as the dye LUMO level must be greater than the conduction band level of nanocrystalline oxides that are commonly used in such devices [43]. Furthermore, the dye HOMO level is less than the redox potential of the electrolyte. The value found for LUMO level is $-3.094 \mathrm{eV}$ and for the HOMO level $-6.240 \mathrm{eV}(\mathrm{Cu}$ complex cation). We also calculated the influence of anion species considering hexafluorophosphate (PF6) and chlorine $\left(\mathrm{Cl}^{-}\right)$. The diagram in Figure 7 illustrates how little activity these species contribute to the energy levels and that these levels meet the requirements. The band gap of $\mathrm{Cu}(\mathrm{I})$ biquinoline dye has a value of $3.146 \mathrm{eV}$, which is a value suitable for its consideration as a potential application in photovoltaic devices. 
Figure 6. Highest occupied molecular orbitals (HOMO) and lowest unoccupied molecular orbitals (LUMO) orbitals of $\mathrm{Cu}$ biquinoline dye with M06/LANL2DZ + DZVP level of calculation.

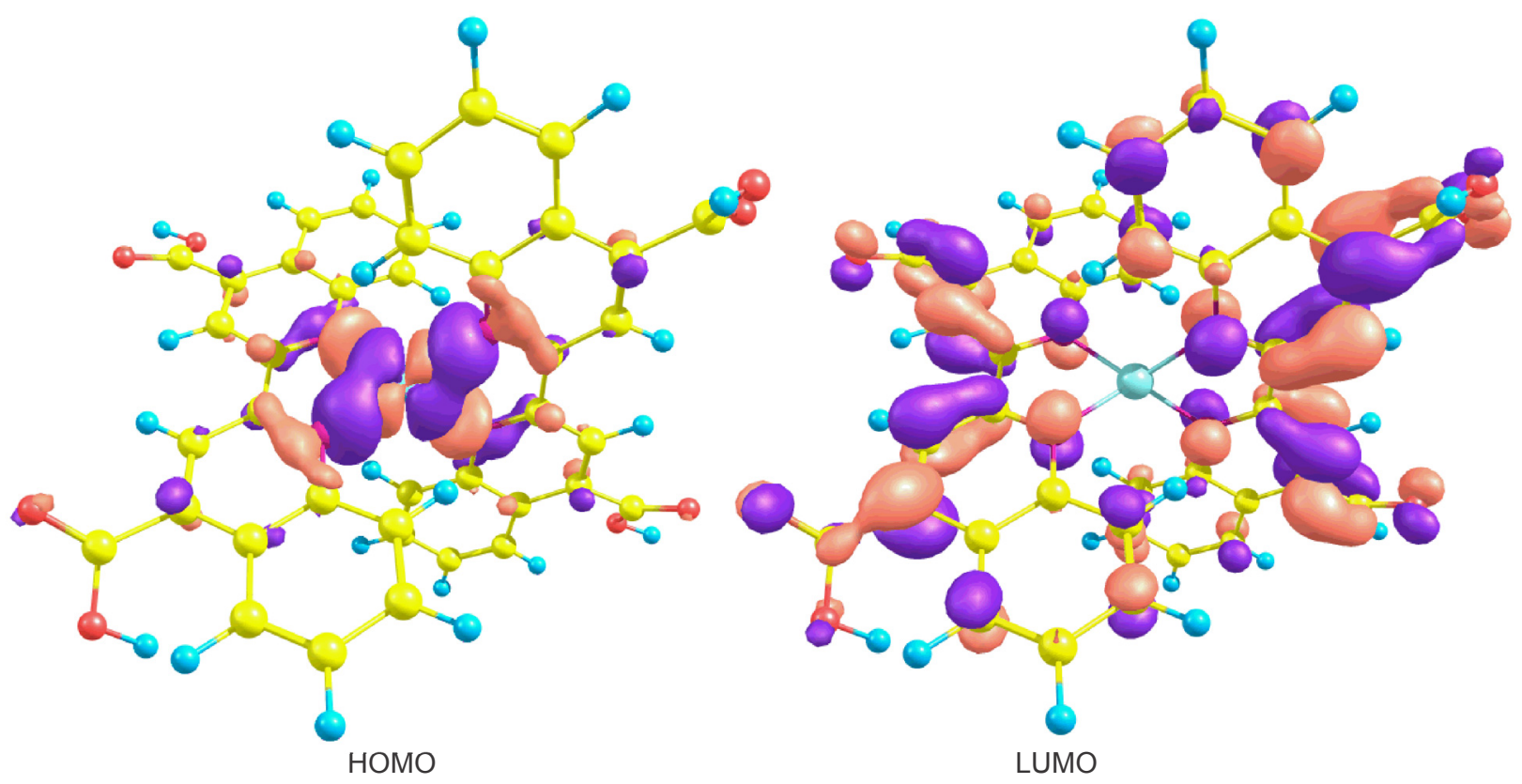

Figure 7. Molecular orbital energy level diagram.

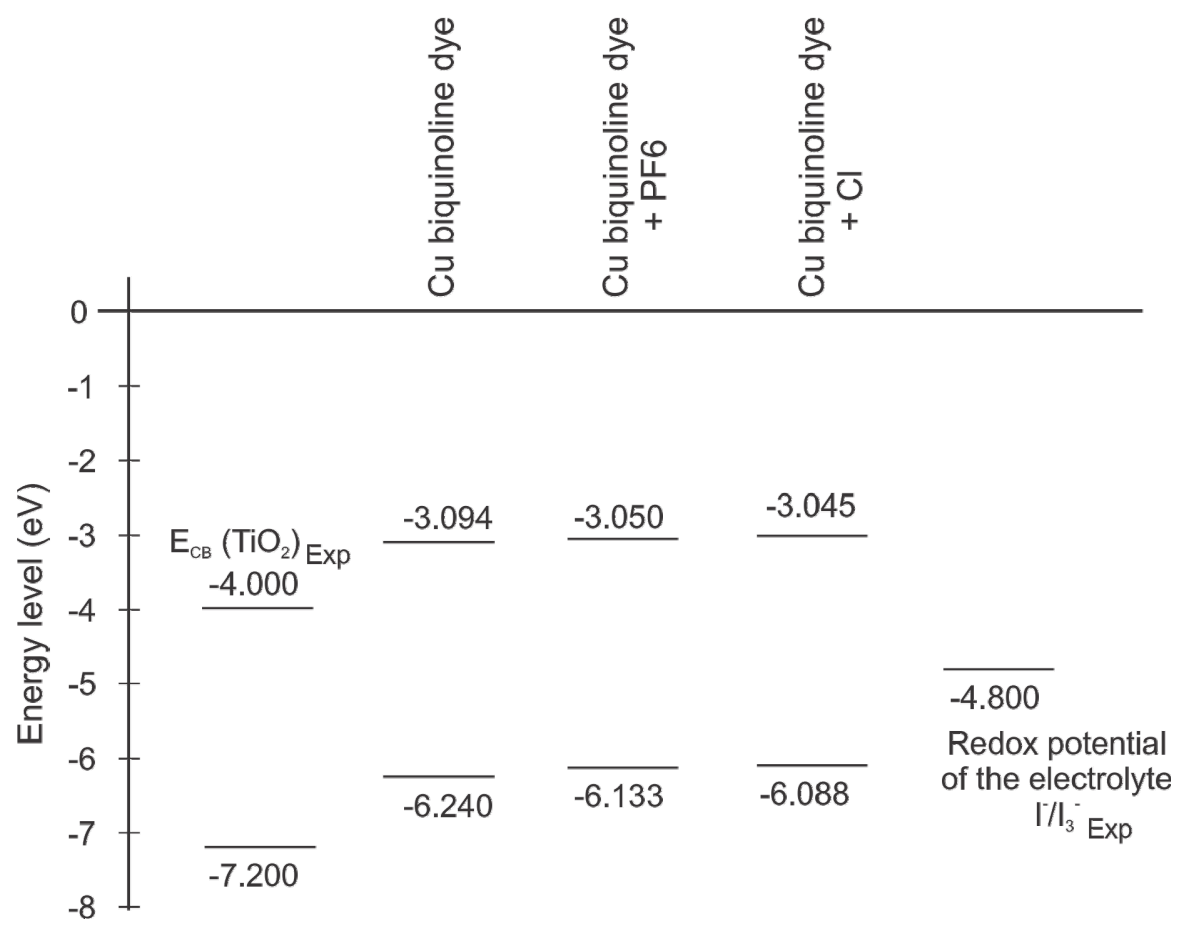

The values of the total dipole moment and the isotropic polarizability at the fundamental state obtained at the M06/LANL2DZ + DZVP level of calculation are 5.63 debye and 838.56 bohr $^{3}$, respectively. Chemical reactivity parameters were obtained by energy calculations (neutral and ionic state), taking into account the ground state geometry optimization. These parameters are the 
electronegativity $(\chi=7.30 \mathrm{eV})$, chemical hardness $(\eta=2.50 \mathrm{eV})$ and electrophilic index $(\omega=10.64 \mathrm{eV})$. These results are of great importance, since they can be used during synthesis to determine the solubility and chemical reactivity of the molecule, and they can also be employed in photovoltaics, as reported in different studies [44-46].

\section{Experimental Section}

Molecular calculations were carried out with the Gaussian09 code. In this study, we have tested the M06 family of density functionals [47-49] based on the ability to study properties of organometallic compounds; the hybrid functionals B3LYP [50-52] and PBE0 [53] have also been used in other studies demonstrating their predictive capacity. The basis sets used were Double Zeta Valence Polarization (DZVP) [54,55], Los Alamos National Laboratory 2 Double Zeta (LANL2DZ) [56-59] and split-valence Pople-type 6-31G(d) [60]. Table 5 shows the use of the basic sets for each of the atoms composing the molecular system.

Table 5. Basis sets used in this study.

\begin{tabular}{ccc}
\hline & Basis set & Atoms \\
\hline \multirow{2}{*}{ Approach 1 } & LANL2DZ & $\mathrm{C}, \mathrm{H}, \mathrm{O}$ and $\mathrm{N}$ \\
& DZVP & $\mathrm{Cu}$ \\
\hline Approach 2 & LANL2DZ & $\mathrm{C}, \mathrm{H}, \mathrm{O}, \mathrm{N}$, and $\mathrm{Cu}$ \\
\hline \multirow{2}{*}{ Approach 3 } & 6-31G(d) & $\mathrm{C}, \mathrm{H}, \mathrm{O}$ and $\mathrm{N}$ \\
& DZVP & $\mathrm{Cu}$ \\
\hline
\end{tabular}

Molecular structure calculations of the ground state were obtained by the established technique in Gaussian 09W. The strength constants and vibrational frequencies were determined via analytic frequency calculations on stationary points obtained after geometry optimization. Both calculations were carried out at the same theory level. Ultraviolet-Visible spectra (UV-Vis) were simulated using the TD-DFT approach; solvent effects sdfd taken into account by an implicit approach, namely the polarizable continuum model (PCM) [61], using the non-equilibrium version of the IEF-PCM model [62], with methanol being considered as solvent. The equations were solved for 20 excited states. The infrared (IR) and UV-Vis spectra were analyzed using the program SWizard $[63,64]$.

In this work we calculated the total dipole moment $(\mu)$ and the isotropic polarizability $(\alpha)$. The molecular dipole moment is an experimental measure of the charge distribution in a molecule. It is difficult to accurately evaluate the global electron distribution in a molecule because it involves all the multipoles. The polarizability contributes in a significant way to the understanding of the response of the system facing an external field. On the other hand, using the DFT framework makes it possible to find the chemical reactivity descriptor values, such as electron affinity, ionization potential, electronegativity, hardness and electrophilic index. All these values were obtained using system energy calculations. 


\section{Conclusions}

In this work, we studied a copper complex with a polypyridine-type ligand. A set of methodologies suitable for the study of this type of molecular systems was applied, and based on a comparison of experimental data with theoretical calculations, we elected the M06/LANL2DZ + DZVP level of calculation, which was found to be the better approach. The molecular system characterization includes the geometry optimization, the calculation of vibrations of functional groups, total dipole moment, isotropic polarizability, molecular orbitals, and chemical reactivity parameters. The molecular orbital energy indicates an energy gap of $3.146 \mathrm{eV}$ in the $\mathrm{Cu}$ biquinoline dye. The influence of anion species such as hexafluorophosphate and chlorine does not contribute to the energy levels. Analyzing the data makes it possible to find potential applications for this dye in photovoltaic devices.

The M06/LANL2DZ + DZVP level of calculation can be used as a useful tool for studying the molecular structure and electronic properties of $\mathrm{Cu}$ biquinoline dye, as well as other structures derived from it.

\section{Acknowledgments}

This work was supported by Consejo Nacional de Ciencia y Tecnología (CONACYT) and Centro de Investigación en Materiales Avanzados, S.C. (CIMAV), and Universidad Autónoma de Sinaloa and Dirección de Investigación y Posgrado by PROFAPI 2011/043. J.B.L. gratefully acknowledges a fellowship from CONACYT. D.G.M and N.F.H. are researchers of CIMAV and CONACYT.

\section{References}

1. Bobicki, E.R.; Liu, Q.; Xu, Z.; Zeng, H. Carbon capture and storage using alkaline industrial wastes. Prog. Energy Combust. Sci. 2012, 38, 302-320.

2. Canadell, J.G.; Le Quéré, C.; Raupach, M.R.; Field, C.B.; Buitenhuis, E.T.; Ciais, P.; Conway, T.J.; Gillett, N.P.; Houghton, R.A.; Marland, G. Contributions to accelerating atmospheric $\mathrm{CO}_{2}$ growth from economic activity, carbon intensity, and efficiency of natural sinks. Proc. Natl. Acad. Sci. USA 2007, 104, 18866-18870.

3. Heintz, A. Solar energy combined with chemical reactive systems for the production and storage of sustainable energy: A review of thermodynamic principles. J. Chem. Thermodyn. 2012, 46, 99-108.

4. Hoevenaars, E.J.; Crawford, C.A. Implications of temporal resolution for modeling renewables-based power systems. Renew. Energy 2012, 41, 285-293.

5. Song, Y.; Wang, J.; Dai, Y.; Zhou, E. Thermodynamic analysis of a transcritical $\mathrm{CO}_{2}$ power cycle driven by solar energy with liquified natural gas as its heat sink. Appl. Energy 2012, 92, 194-203.

6. Chu, H.-C.; Sahu, D.; Hsu, Y.-C.; Padhy, H.; Patra, D.; Lin, J.-T.S.; Bhattacharya, D.; Lu, K.-L.; Wei, K.-H.; Lin, H.-C. Structural planarity and conjugation effects of novel symmetrical acceptor-donor-acceptor organic sensitizers on dye-sensitized solar cells. Dyes Pigment. 2012, 93, 1488-1497.

7. O’Regan, B.; Gratzel, M. A low-cost, high-efficiency solar cell based on dye-sensitized colloidal TiO2 films. Nature 1991, 353, 737-740.

8. Gratzel, M. Photoelectrochemical cells. Nature 2001, 414, 338-344. 
9. Wang, P.; Zakeeruddin, S.M.; Moser, J.E.; Nazeeruddin, M.K.; Sekiguchi, T.; Gratzel, M. A stable quasi-solid-state dye-sensitized solar cell with an amphiphilic ruthenium sensitizer and polymer gel electrolyte. Nat. Mater. 2003, 2, 402-407.

10. Cheng, X.; Sun, S.; Liang, M.; Shi, Y.; Sun, Z.; Xue, S. Organic dyes incorporating the cyclopentadithiophene moiety for efficient dye-sensitized solar cells. Dyes Pigment. 2012, 92, 1292-1299.

11. Saito, Y.; Fukuri, N.; Senadeera, R.; Kitamura, T.; Wada, Y.; Yanagida, S. Solid state dye sensitized solar cells using in situ polymerized PEDOTs as hole conductor. Electrochem. Commun. 2004, 6, 71-74.

12. Qiu, F.L.; Fisher, A.C.; Walker, A.B.; Peter, L.M. The distribution of photoinjected electrons a dye-sensitized nanocrystalline $\mathrm{TiO}_{2}$ solar cell modelled by a boundary element method. Electrochem. Commun. 2003, 5, 711-716.

13. Asbury, J.B.; Ellingson, R.J.; Ghosh, H.N.; Ferrere, S.; Nozik, A.J.; Lian, T. Femtosecond IR study of excited-state relaxation and electron-injection dynamics of $\mathrm{Ru}(\mathrm{dcbpy})_{2}(\mathrm{NCS})_{2}$ in solution and on nanocrystalline $\mathrm{TiO}_{2}$ and $\mathrm{Al}_{2} \mathrm{O}_{3}$ thin films. J. Phys. Chem. B 1999, 103, 3110-3119.

14. Chen, J.G.; Chen, C.Y.; Wu, S.J.; Li, J.Y.; Wu, C.G.; Ho, K.C. On the photophysical and electrochemical studies of dye-sensitized solar cells with the new dye CYC-B1. Sol. Energy Mater. Sol. Cells 2008, 92, 1723-1727.

15. Heimer, T.A.; Heilweil, E.J.; Bignozzi, C.A.; Meyer, G.J. Electron injection, recombination, and halide oxidation dynamics at dye-sensitized metal oxide interfaces. J. Phys. Chem. A 2000, 104, 4256-4262.

16. Figgemeier, E.; Hagfeldt, A. Are dye-sensitized nano-structured solar cells stable? An overview of device testing and component analyses. Int. J. Photoenergy 2004, 6, 127-140.

17. Grätzel, M. Nanocrystalline Electronic Junctions. In Studies in Surface Science and Catalysis; Prashant, V.K., Dan, M., Eds.; Elsevier: Amsterdam, The Netherlands, 1997; Volume 103, pp. 353-375.

18. Grätzel, M. Dye-sensitized solar cells. J. Photochem. Photobiol. C 2003, 4, 145-153.

19. Kamat, P.V.; Haria, M.; Hotchandani, S. $\mathrm{C}_{60}$ Cluster as an electron shuttle in a $\mathrm{Ru}(\mathrm{II})$-polypyridyl sensitizer-based photochemical solar cell. J. Phys. Chem. B 2004, 108, 5166-5170.

20. Cao, J.; Sun, J.Z.; Hong, J.; Yang, X.G.; Chen, H.Z.; Wang, M. Direct observation of microscopic photoinduced charge redistribution on $\mathrm{TiO}_{2}$ film sensitized by chloroaluminum phthalocyanine and perylenediimide. Appl. Phys. Lett. 2003, 83, 1896-1898.

21. Zhang, C.-R.; Liu, Z.-J.; Chen, Y.-H.; Chen, H.-S.; Wu, Y.-Z.; Yuan, L.-H. DFT and TDDFT study on organic dye sensitizers D5, DST and DSS for solar cells. J. Mol. Struct. Theochem 2009, 899, 86-93.

22. Ham, H.W.; Kim, Y.S. Theoretical study of indoline dyes for dye-sensitized solar cells. Thin Solid Films 2010, 518, 6558-6563.

23. Zhang, C.R.; Liu, Z.J.; Chen, Y.H.; Chen, H.S.; Wu, Y.Z.; Feng, W.; Wang, D.B. DFT and TD-DFT study on structure and properties of organic dye sensitizer TA-St-CA. Curr. Appl. Phys. 2010, 10, $77-83$.

24. De Angelis, F. Direct vs. indirect injection mechanisms in perylene dye-sensitized solar cells: A DFT/TDDFT investigation. Chem. Phys. Lett. 2010, 493, 323-327. 
25. Zhao, J.; Ji, S.; Wu, W.; Wu, W.; Guo, H.; Sun, J.; Sun, H.; Liu, Y.; Li, Q.; Huang, L. Transition metal complexes with strong absorption of visible light and long-lived triplet excited states: From molecular design to applications. RSC Adv. 2012, 2, 1712-1728.

26. Li, G.; Ray, L.; Glass, E.N.; Kovnir, K.; Khoroshutin, A.; Gorelsky, S.I.; Shatruk, M. Synthesis of panchromatic $\mathrm{Ru}(\mathrm{II})$ thienyl-dipyrrin complexes and evaluation of their light-harvesting capacity. Inorg. Chem. 2012, 51, 1614-1624.

27. Vougioukalakis, G.C.; Philippopoulos, A.I.; Stergiopoulos, T.; Falaras, P. Contributions to the development of ruthenium-based sensitizers for dye-sensitized solar cells. Coord. Chem. Rev. 2011, 255, 2602-2621.

28. Alonso-Vante, N.; Nierengarten, J.F.; Sauvage, J.P. Spectral sensitization of large-band-gap semiconductors (thin films and ceramics) by a carboxylated bis(1,10-phenanthroline)copper(I) complex. J. Chem. Soc. Dalton Trans. 1994, 1649-1654, doi:10.1039/DT9940001649.

29. Deng, J.; Xiu, Q.; Guo, L.; Zhang, L.; Wen, G.; Zhong, C. Branched chain polymeric metal complexes containing $\mathrm{Co}(\mathrm{II})$ or $\mathrm{Ni}(\mathrm{II})$ complexes with a donor- $\pi$-acceptor architecture: Synthesis, characterization, and photovoltaic applications. J. Mater. Sci. 2012, 47, 3383-3390.

30. Barrientos, L.; Araneda, C.; Loeb, B.; Crivelli, I.G. Synthesis, spectroscopic and electrochemical characterization of copper(I) complexes with functionalized pyrazino[2,3-f]-1,10-phenanthroline. Polyhedron 2008, 27, 1287-1295.

31. Hohenberg, P.; Kohn, W. Inhomogeneous Electron Gas. Phys. Rev. 1964, 136, B864-B871.

32. Kohn, W.; Sham, L.J. Self-consistent equations including exchange and correlation effects. Phys. Rev. 1965, 140, A1133-A1138.

33. Parr, R.G.; Yang, W. Density-Functional Theory of Atoms and Molecules; Oxford University Press: New York, NY, USA, 1989.

34. Burke, K.; Werschnik, J.; Gross, E.K.U. Time-dependent density functional theory: Past, present, and future. J. Chem. Phys. 2005, 123, 062206.

35. Stratmann, R.E.; Scuseria, G.E.; Frisch, M.J. An efficient implementation of time-dependent density-functional theory for the calculation of excitation energies of large molecules. J. Chem. Phys. 1998, 109, 8218-8224.

36. Bauernschmitt, R.; Ahlrichs, R. Treatment of electronic excitations within the adiabatic approximation of time dependent density functional theory. Chem. Phys. Lett. 1996, 256, 454-464.

37. Frisch, M.J.; Trucks, G.W.; Schlegel, H.B.; Scuseria, G.E.; Robb, M.A.; Cheeseman, J.R.; Scalmani, G.; Barone, V.; Mennucci, B.; Petersson, G.A.; et al. Gaussian 09, Revision A. 02; Gaussian Inc.: Wallingford, CT, USA, 2009.

38. Hernández Redondo, A. Copper(I) Polypyridine Complexes: The Sensitizers of the Future for Dye-Sensitized Solar Cells (DSSCs). Ph.D. Thesis, University of Basel, 2009.

39. Green, M.A. Solar Cells: Operating Principles, Technology and Systems Applications; Prentice-Hall, Inc.: Englewood Cliffs, NJ, USA, 1982.

40. Lu, X.; Wu, C.-M.L.; Wei, S.; Guo, W. DFT/TD-DFT investigation of electronic structures and spectra properties of Cu-based dye sensitizers. J. Phys. Chem. A 2010, 114, 1178-1184. 
41. Bessho, T.; Constable, E.C.; Graetzel, M.; Hernandez Redondo, A.; Housecroft, C.E.; Kylberg, W.; Nazeeruddin, M.K.; Neuburger, M.; Schaffner, S. An element of surprise-efficient copper-functionalized dye-sensitized solar cells. Chem. Commun. 2008, 3717-3719, doi:10.1039/B808491B.

42. Bozic-Weber, B.; Constable, E.C.; Housecroft, C.E.; Neuburger, M.; Price, J.R. Sticky complexes: Carboxylic acid-functionalized N-phenylpyridin-2-ylmethanimine ligands as anchoring domains for copper and ruthenium dye-sensitized solar cells. Dalton Trans. 2010, 39, 3585-3594.

43. Lu, X.; Wei, S.; Wu, C.-M.L.; Li, S.; Guo, W. Can polypyridyl Cu(I)-based complexes provide promising sensitizers for dye-sensitized solar cells? A theoretical insight into $\mathrm{Cu}(\mathrm{I})$ versus $\mathrm{Ru}(\mathrm{II})$ sensitizers. J. Phys. Chem. C 2011, 115, 3753-3761.

44. De Angelis, F.; Fantacci, S.; Sgamellotti, A. An integrated computational tool for the study of the optical properties of nanoscale devices: Application to solar cells and molecular wires. Theor. Chem. Acc. 2007, 117, 1093-1104.

45. Weng, Y.-X.; Wang, Y.-Q.; Asbury, J.B.; Ghosh, H.N.; Lian, T. Back electron transfer from $\mathrm{TiO}_{2}$ nanoparticles to $\mathrm{Fe}^{\mathrm{III}}(\mathrm{CN})_{6}{ }^{3-}$ : Origin of non-single-exponential and particle size independent dynamics. J. Phys. Chem. B 1999, 104, 93-104.

46. Sharma, S.K.; Inamdar, A.I.; Im, H.; Kim, B.G.; Patil, P.S. Morphology dependent dye-sensitized solar cell properties of nanocrystalline zinc oxide thin films. J. Alloy. Compd. 2011, 509, 2127-2131.

47. Zhao, Y.; Truhlar, D.G. A new local density functional for main-group thermochemistry, transition metal bonding, thermochemical kinetics, and noncovalent interactions. J. Chem. Phys. 2006, 125, 194101-194118.

48. Zhao, Y.; Truhlar, D.G. Density functional for spectroscopy: No long-range self-interaction error, good performance for rydberg and charge-transfer states, and better performance on average than B3LYP for ground states. J. Phys. Chem. A 2006, 110, 13126-13130.

49. Zhao, Y.; Truhlar, D. The M06 suite of density functionals for main group thermochemistry, thermochemical kinetics, noncovalent interactions, excited states, and transition elements: Two new functionals and systematic testing of four M06-class functionals and 12 other functionals. Theor. Chem. Acc. 2008, 120, 215-241.

50. Becke, A.D. Density-functional thermochemistry. III. The role of exact exchange. J. Chem. Phys. 1993, 98, 5648-5652.

51. Becke, A.D. Density-functional exchange-energy approximation with correct asymptotic behavior. Phys. Rev. A 1988, 38, 3098-3100.

52. Lee, C.; Yang, W.; Parr, R.G. Development of the Colle-Salvetti correlation-energy formula into a functional of the electron density. Phys. Rev. B 1988, 37, 785-789.

53. Adamo, C.; Barone, V. Toward reliable density functional methods without adjustable parameters: The PBE0 model. J. Chem. Phys. 1999, 110, 6158-6170.

54. Godbout, N.; Salahub, D.R.; Andzelm, J.; Wimmer, E. Optimization of Gaussian-type basis sets for local spin density functional calculations. Part I. Boron through neon, optimization technique and validation. Can. J. Chem. 1992, 70, 560-571. 
55. Sosa, C.; Andzelm, J.; Elkin, B.C.; Wimmer, E.; Dobbs, K.D.; Dixon, D.A. A local density functional study of the structure and vibrational frequencies of molecular transition-metal compounds. J. Chem. Phys. 1992, 96, 6630-6636.

56. Dunning, T.H., Jr.; Hay, P.J. Methods of Electronic Structure Theory; Plenum: New York, NY, USA, 1976; Volume 3.

57. Hay, P.J.; Wadt, W.R. Ab initio effective core potentials for molecular calculations. Potentials for the transition metal atoms Sc to Hg. J. Chem. Phys. 1985, 82, 270-283.

58. Wadt, W.R.; Hay, P.J. Ab initio effective core potentials for molecular calculations. Potentials for main group elements Na to Bi. J. Chem. Phys. 1985, 82, 284-298.

59. Hay, P.J.; Wadt, W.R. Ab initio effective core potentials for molecular calculations. Potentials for $\mathrm{K}$ to $\mathrm{Au}$ including the outermost core orbitals. J. Chem. Phys. 1985, 82, 299-310.

60. Francl, M.M.; Pietro, W.J.; Hehre, W.J.; Binkley, J.S.; Gordon, M.S.; DeFrees, D.J.; Pople, J.A. Self-consistent molecular orbital methods. XXIII. A polarization-type basis set for second-row elements. J. Chem. Phys. 1982, 77, 3654-3665.

61. Tomasi, J.; Mennucci, B.; Cammi, R. Quantum Mechanical Continuum Solvation Models. Chem. Rev. 2005, 105, 2999-3094.

62. Cossi, M.; Barone, V. Time-dependent density functional theory for molecules in liquid solutions. J. Chem. Phys. 2001, 115, 4708-4717.

63. Gorelsky, S.I. SWizard program. Available online: http://www.sg-chem.net/ (accessed on 30 April 2012).

64. Gorelsky, S.I.; Lever, A.B.P. Electronic structure and spectra of ruthenium diimine complexes by density functional theory and INDO/S. Comparison of the two methods. J. Organomet. Chem. 2001, 635, 187-196.

(C) 2012 by the authors; licensee MDPI, Basel, Switzerland. This article is an open access article distributed under the terms and conditions of the Creative Commons Attribution license (http://creativecommons.org/licenses/by/3.0/). 